\title{
Los lugares colombinos de Huelva: historia, cultura y naturaleza
}

Diego Ropero-Regidor | Archivo Histórico Municipal, Biblioteca Iberoamericana de Moguer

URL de la contribución <www.iaph.es/revistaph/index.php/revistaph/issue/view/4292>

\section{RESUMEN}

La historiografía americanista dedicó en el pasado siglo una atención especial a los lugares colombinos de la provincia de Huelva. Los preparativos y la realización del viaje de Colón forman parte del relato histórico de La Rábida, Palos de la Frontera y Moguer, tríada espacial con el tiempo dentro que ha sabido recuperar y potenciar un legado que comparten como una de las señas de identidad que más han marcado su devenir. En el siglo XIX se dieron las condiciones para que el monasterio de La Rábida no fuera destruido, sumándose a los planes de su rehabilitación el gobierno y muchas personalidades de la política y la cultura de España y América. EI IV Centenario del Descubrimiento supuso el punto de inflexión hacia la modernidad; desde entonces este rincón onubense, su historia, los edificios vinculados a la gesta colombina, como el modesto cenobio franciscano, la iglesia de San Jorge, de Palos, y el monasterio de Santa Clara, de Moguer, y su entorno urbano y paisajístico proyectan unos valores que son reconocidos por la sociedad en general. Las últimas y recientes inversiones públicas en estos lugares colombinos, especialmente las realizadas en torno a 1992, fueron destinadas a restaurar y revitalizar sus monumentos históricoartísticos, y, además, a dotar dicho espacio con nuevas instalaciones culturales. Las huellas de Colón, los Pinzón y los hermanos Niño, y las tres naves descubridoras -cuyas réplicas se encuentran en el recinto museístico del Muelle de las Carabelas-, igual que entonces, siguen rememorando en el estuario del río Tinto una de las epopeyas más universales.

\section{Palabras clave}

América | Colón | Descubrimiento | España | Gestión | La Rábida (Huelva) | Lugares colombinos | Moguer (Huelva) | Palos de la Frontera (Huelva) | Patrimonio | 1492 | 


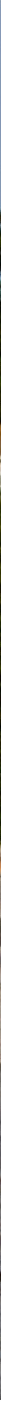

Santuario de Nuestra Señora de la Cinta. Huelva | foto J. Miguel Marchena 
El espacio que alberga los lugares colombinos en la provincia de Huelva proyecta la memoria de la aventura americana, episodio que ha tenido momentos de olvido y reivindicaciones. En 1828, el escritor Washington Irving visitó dichos lugares y alertó al mundo del abandono del monasterio de La Rábida, epicentro donde Colón fue arropado por los frailes franciscanos que le pusieron en contacto con armadores y navegantes notables de Palos y Moguer. Tras siete años deambulando por la corte en busca de apoyos para su viaje, los Reyes Católicos finalmente dispusieron que fueran atendidas sus demandas. El 17 de abril de 1492 se firmaron las Capitulaciones en Santa $\mathrm{Fe}$, en las inmediaciones de Granada, capital del reino nazarí que había sido tomada a principios de ese año. El apoyo de los frailes Antonio de Marchena y Juan Pérez, y de Martín Alonso Pinzón, de Palos, y los hermanos Niño, de Moguer, fue decisivo para conseguir las naves y atraer a la tripulación que protagonizaron una de las epopeyas más importantes de la historia de la humanidad. El viaje de descubrimiento de la nao Santa María y las carabelas Pinta y Niña, revolucionó -en opinión de Johannes Stradanus (1580)- la forma de pensar del Renacimiento.

La recuperación para el acervo cultural de tan singular espacio han llevado a los responsables de su gestión a optimizar los recursos de los elementos que componen dicho ámbito, con el objetivo de destacar su valor excepcional universal para que La Rábida y los lugares colombinos sean incluidos en la lista de Patrimonio de la Humanidad. Las reivindicaciones del protagonismo onubense en el Descubrimiento se inician en el siglo XIX, a partir de las reacciones que provocó la desaparición del modesto cenobio rabideño tras la desamortización. El gobernador Mariano Alonso del Castillo influyó para impedir su derribo. Tras la oportuna visita de los duques de Montpensier, el monasterio fue declarado monumento nacional en 1856. Con posterioridad se sucedieron intervenciones de calado en el edificio y su entorno a cargo del arquitecto Ricardo Velázquez Bosco para que pudieran acoger los fastos del IV Centenario del Descubrimiento.

Tras varias décadas sin avances significativos, salvo algunos eventos y actuaciones puntuales como el vuelo transatlántico del hidroavión Plus Ultra (1926) y la erección del monumento a Colón en la Punta del Sebo (1929), obra de la artista norteamericana Gertrudis Whitney, fue creada la Universidad Hispanoamericana (1943), institución que ha pasado por distintas etapas, aunque sigue profundizando en las estrechas relaciones que Huelva mantiene con Iberoamérica (en la actualidad es una de las sedes de la UNIA). Coincidiendo con los planes de desarrollo industrial en la década de los sesenta de siglo pasado, los lugares colombinos fueron declarados conjunto histórico-artístico, protección que ha sido reforzada y ampliada recientemente como sitio histórico en el Catálogo General del Patrimonio Histórico Andaluz. En 1992, fecha emblemática para la comunidad iberoamericana, La Rábida, Palos de la Frontera y Moguer cogieron de nuevo el testigo con 


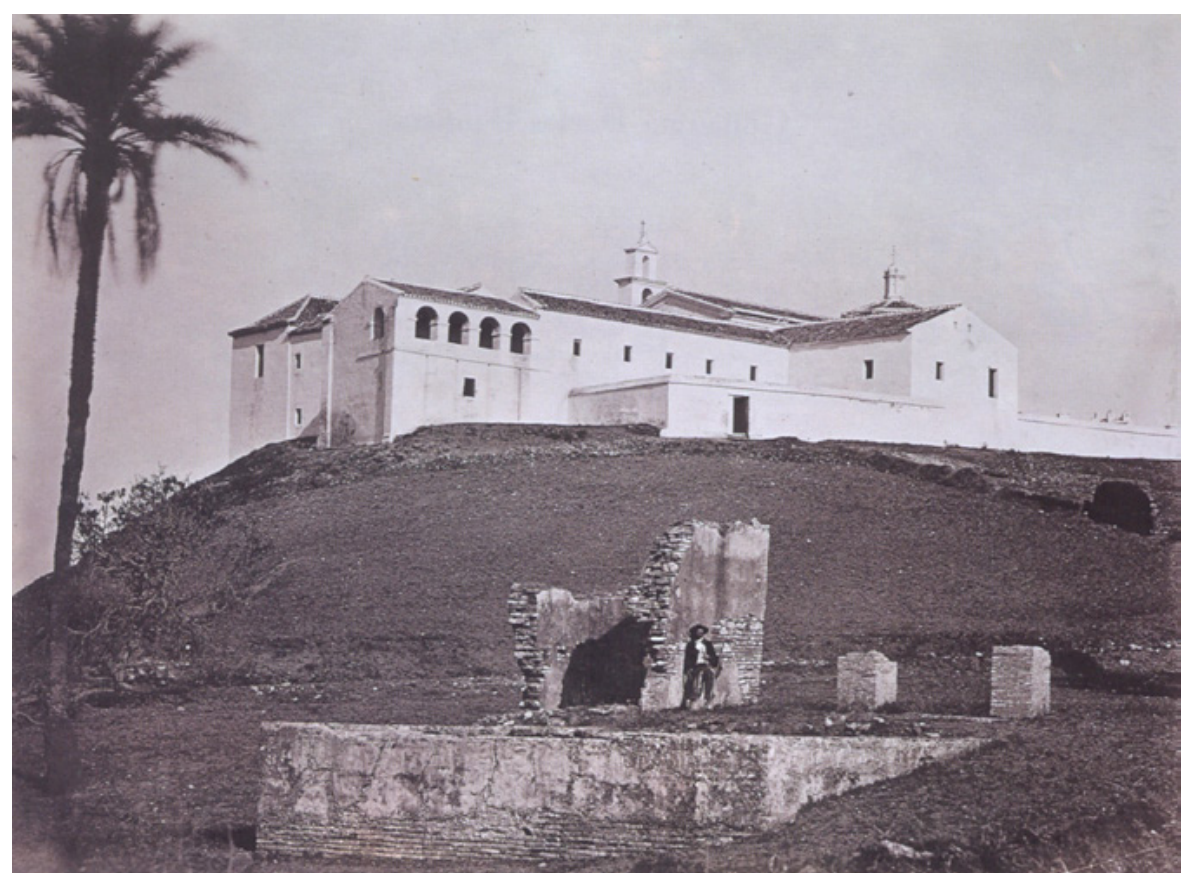

motivo del $\vee$ Centenario. En esta ocasión se produjo un avance extraordinario en cuanto a la modernización de programas, infraestructuras y nuevas dotaciones para los espacios colombinos: reformas y ampliación del monasterio, construcción del auditorio y edificio administrativo del parque botánico "Celestino Mutis", en La Rábida; rehabilitaciones de los conventos de Santa Clara y San Francisco, y construcción del teatro Felipe Godínez, en Moguer; iglesia de San Jorge, de Palos; y el Gran Teatro y la Casa Colón, en Huelva. También se realizaron mejoras en la red viaria con la puesta en servicio de la autopista del $\vee$ Centenario, los puentes del Odiel y el internacional del Guadiana. Los reyes visitaron los lugares colombinos y en el monasterio de La Rábida hubo un consejo de ministros presidido por el monarca. Al año siguiente, el papa Juan Pablo II visitó las poblaciones colombinas, culminando en La Rábida su periplo con la coronación de la imagen de la patrona de Palos de la Frontera.

La Rábida y los lugares colombinos gravitan sobre una zona de escarpes y marismas con el río Tinto que desemboca en un amplio estuario hacia donde viene a morir también su hermano el Odiel. Este entorno, formado de gravas y arenas del Pleistoceno inferior, fue en la antigüedad asentamiento de tartesios, romanos y árabes, y en la época del Descubrimiento refugio estratégico de embarcaciones autóctonas y extranjeras. La ciencia náutica y la pericia de sus marineros atrajeron la atención de Cristóbal Colón, quien debía tener información precisa de ellos por los viajes comerciales que realizaban a Canarias y la costa africana (Guinea y Mina del Oro) donde se con-
El convento de La Rábida, 1875. José Spreafico | foto Biblioteca del Palacio Real, Madrid, reproducida en ROPERO-REGIDOR, D. (dir.) (1992) Los lugares colombinos y su entorno. Madrid: Fundación Ramón Areces, p. 96 

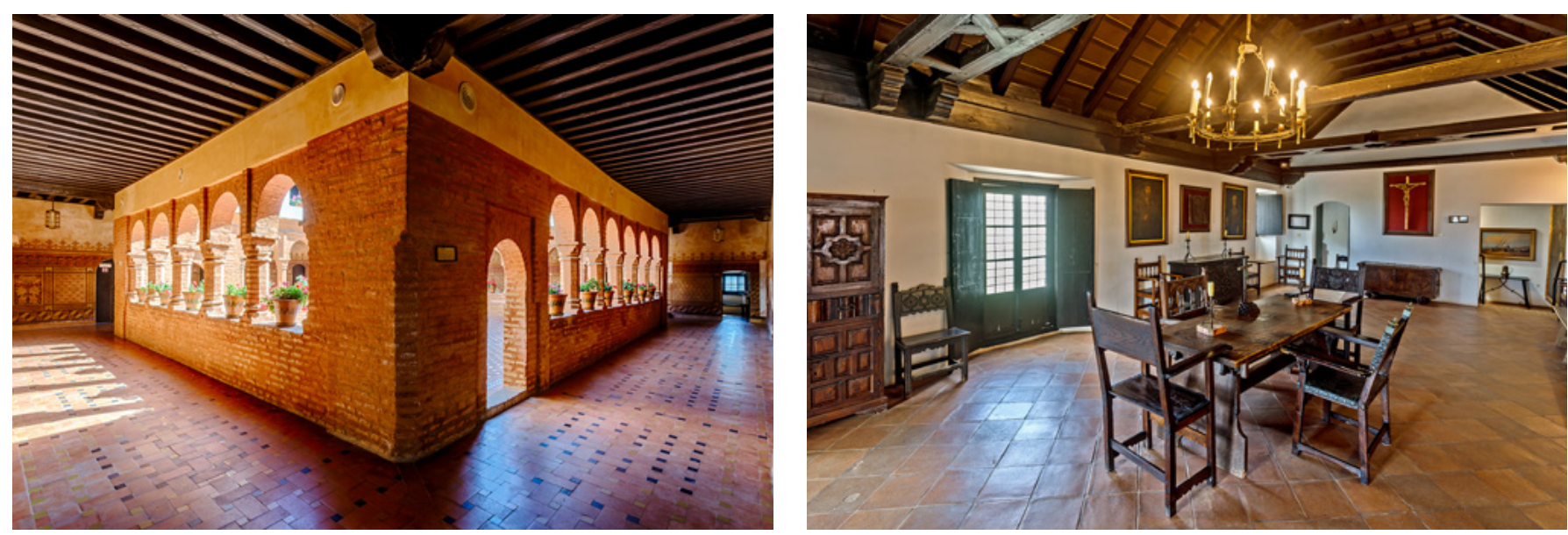

A la izquierda, claustro mudéjar del monasterio de La Rábida

A la derecha, sala del Padre Marchena en el convento de La Rábida | fotos Miguel Ángel Muñoz

centraban para las pesquerías y practicaban el corsarismo. En la Baja Edad Media, Palos, Moguer y Huelva eran poblaciones volcadas al mar, compartían negocios y embarcaciones y, aunque había rivalidad, nunca llegó la sangre al río, pues supieron aprovechar las oportunidades. Sus habitantes eran gente recia y competente, nada timorata, sabios por naturaleza, de lo contrario habría sido improbable que se sumaran los mejores marinos a la expedición colombina.

Desde el estratégico emplazamiento del monasterio de La Rábida, se contempla todo el estuario de los ríos Tinto y Odiel. Es, junto con la iglesia parroquial de San Jorge de Palos y el monasterio de Santa Clara de Moguer, uno de los monumentos colombinos. Sobre su origen existen opiniones encontradas; no obstante, los restos arqueológicos romanos e islámicos corroboran que esta zona ya estuvo habitada en la antigüedad. La fundación del convento parte del año 1412; ya entonces existía en dicho emplazamiento un marabito o ribat. Se trata de una construcción gótico-mudéjar, en la que destaca el uso del ladrillo, tapial y mampostería en muros, así como sillería de piedra en fachada principal, modelo repetido en las iglesias sevillanas de esta época. La fábrica fue completada a lo largo del siglo XV. En etapas posteriores, se llevaron a cabo distintas intervenciones, sobre todo las realizadas en el siglo XVII y en la segunda mitad del XVIII, como la cúpula de la iglesia, la espadaña o la galería alta del claustro mudéjar.

El convento, de factura modesta, nos retrotrae al tipo de cenobio o eremitorio franciscano alejado de los núcleos urbanos (entre 1623 y 1835, La Rábida fue centro de recolección de la Provincia Observante de Andalucía). El acceso al mismo se hace a través de una pequeña portería que conecta con la antigua sacristía donde podemos admirar los frescos de Vázquez Díaz el Poema del Descubrimiento (1929), que narran los momentos previos al viaje colombino, y el claustro de la Hospedería. La iglesia es de planta rectangu- 
lar con capillas laterales y presbiterio. El claustro mudéjar es de la primera mitad del XV; sus galerías son de ladrillo tallado, con arcos de medio punto peraltados, remarcados por alfices y apoyados en columnas octogonales. La planta alta fue construida coincidiendo con las reformas barrocas. En torno al mismo se encuentran las celdas primitivas, el refectorio, la sala capitular y otras dependencias anejas.

El histórico recinto franciscano acoge un museo colombino cuyo programa se complementa con el relato que ofrece el muelle de las Carabelas, donde se encuentran las réplicas de las tres naves que fueron construidas por la Sociedad Estatal con motivo del $\mathrm{V}$ Centenario del Descubrimiento. Otros edificios e instalaciones refuerzan el discurso y la identidad americanista de La Rábida: la Universidad Hispanoamericana (desde 1994 Internacional de Andalucía), el auditorio o foro Iberoamericano, el parque botánico "Celestino Mutis", donde podemos contemplar especies del continente americano, la Casita de Zenobia, la columna del IV Centenario, el monumento a Colón o el
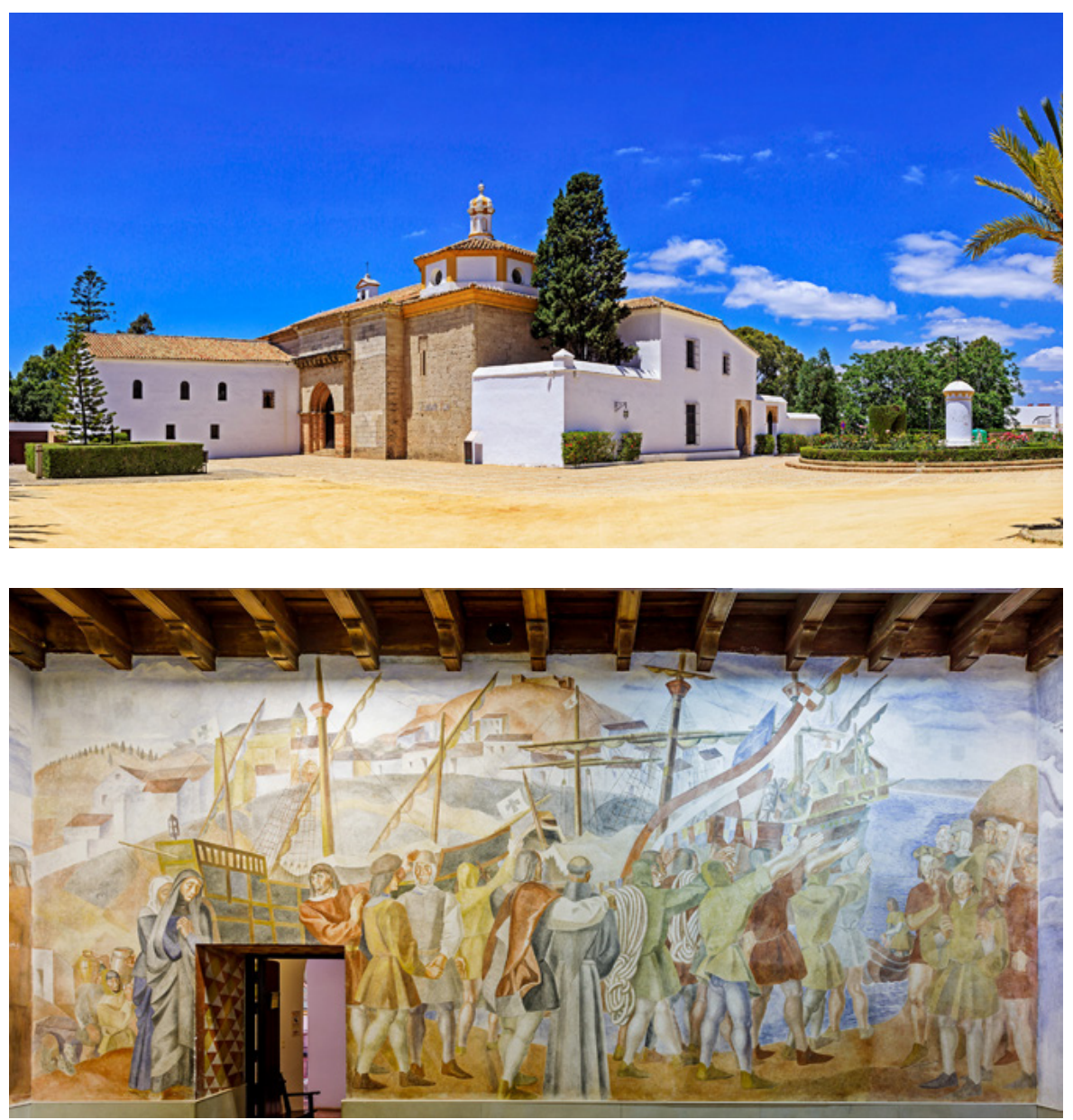

Panorámica del monasterio de La Rábida

Poema del Descubrimiento, "La partida", 1929. Daniel Vázquez Díaz. Monasterio de La Rábida | fotos Miguel Ángel Muñoz 


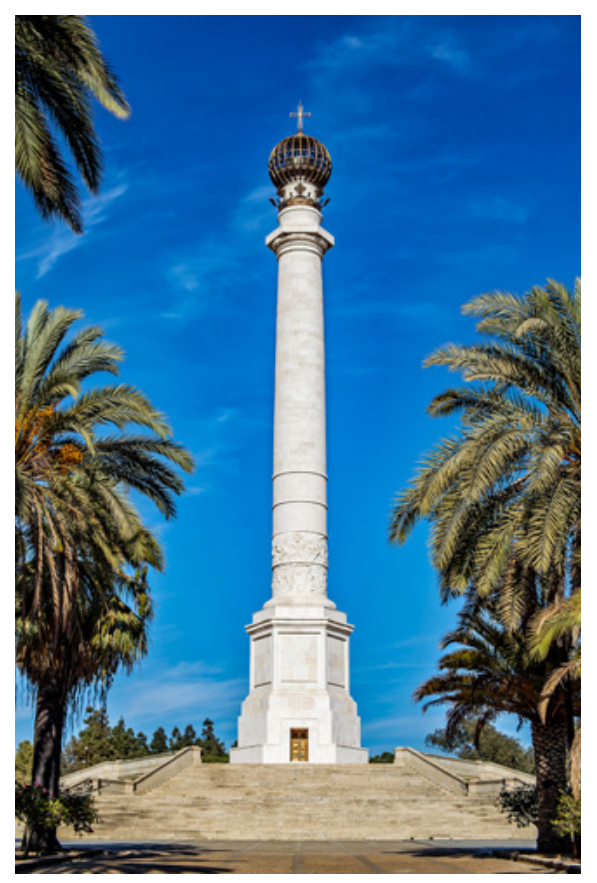

A la izquerda, columna conmemorativa del IV Centenario. La Rábida

Muelle de las Carabelas. La Rábida | fotos Miguel Ángel Muñoz

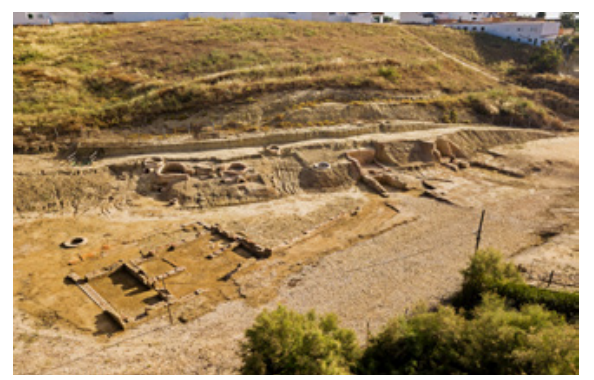

Restos del antiguo puerto de Palos de la Frontera | foto Miguel Ángel Muñoz

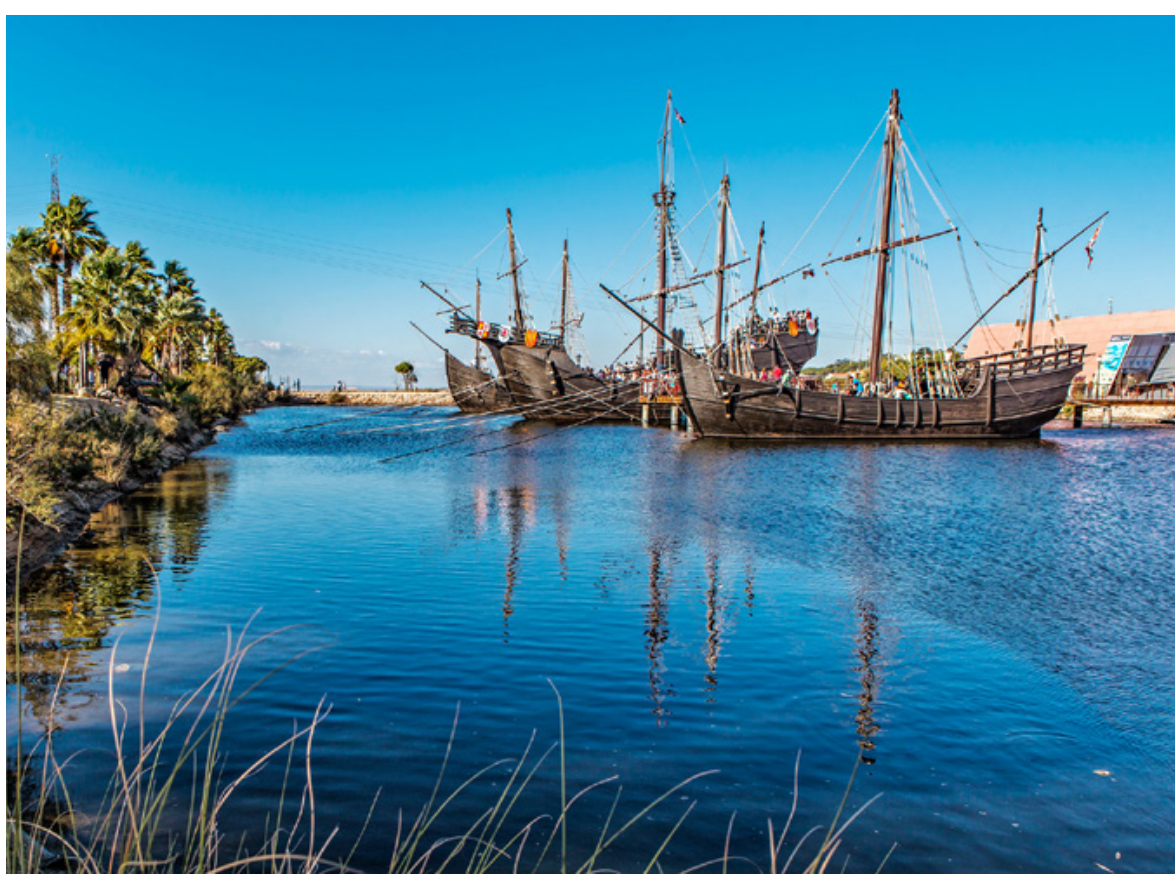

Ícaro, alegoría en homenaje al vuelo Plus Ultra, en el muelle de la Reina. El recinto rabideño cuenta con abundante arboleda, destacando el pino piñonero, y zonas ajardinadas.

Dejamos La Rábida y llegamos a Palos de la Frontera, una población muy pujante dedicada al cultivo del fresón, en cuyo término se localiza gran parte de la industria química, como la refinería y las instalaciones del puerto exterior de Huelva. En torno a la iglesia de San Jorge, edificio gótico-mudéjar construido en el siglo XIV, reformado o ampliado en los siglos XVI-XVIII, tuvo lugar la lectura de la pragmática real que ordenaba a los vecinos a entregar dos carabelas al futuro almirante de las Indias y el alistamiento de la tripulación. En sus inmediaciones se encuentran los restos del castillo, la casa museo de Martín Alonso Pinzón -solar que habitaron el ilustre marino y su familia-, la Fontanilla -un templete que abastecía de agua a la población y a las embarcaciones- y el antiguo puerto, cuyos cimientos han salido recientemente a la luz, tras varios años de campaña arqueológica, en lo que fue una ensenada del río Tinto, navegable en tiempos del Descubrimiento.

Moguer es, después de su vecina Palos de la Frontera, la segunda población colombina por su contribución al Descubrimiento. Si los Pinzón representan la élite entre los navegantes y armadores de la zona, los moguereños hermanos Niño estuvieron a la misma altura. La actividad pesquera, la construcción de barcos en el astillero de la Ribera y el intercambio entre los pueblos vecinos y otras plazas extranjeras, los estamentos sociales más favorecidos, 


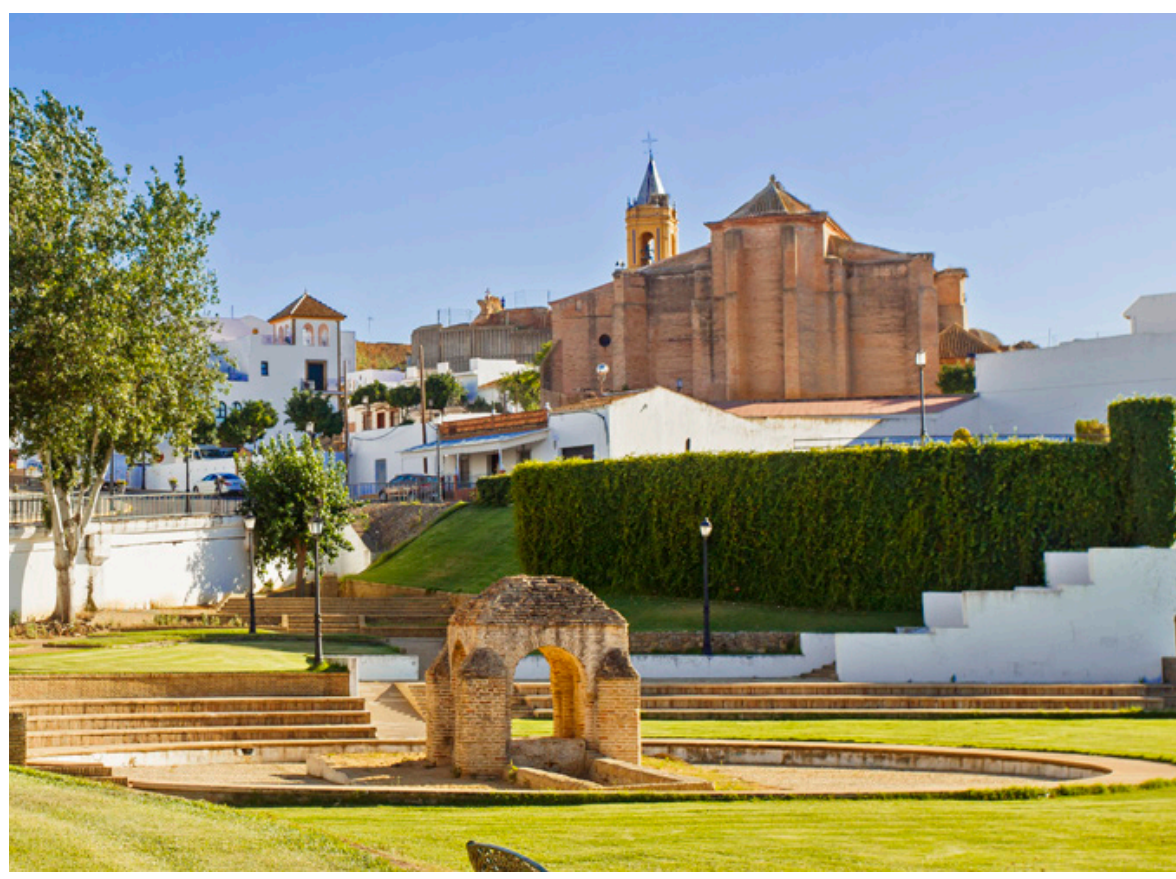

especialmente el religioso y aquellas personas que detentaron el poder local y controlaron la economía, contribuyeron a la prosperidad de la población, tradicionalmente agrícola y marinera, coincidiendo en el tiempo con las visitas que Cristóbal Colón realizó a Moguer, donde también negoció su viaje a las Indias con personas que tenían influencia dentro y fuera de la villa, destacando Inés Enríquez, abadesa del monasterio de Santa Clara, pariente del rey Fernando el Católico y, por supuesto, los hermanos Niño, dueños de la carabela Niña o Santa Clara, construida pocos años antes de la partida en la ribera de Moguer, y cuya participación en los viajes de descubrimiento dejaron huella en la historia de las navegaciones. Los preparativos del viaje se hicieron en Palos y en Moguer; por tanto, fue una empresa colectiva auspiciada por los reyes con el esfuerzo de Colón y la contribución de los Pinzón y los Niño y el resto de la marinería del estuario del Tinto.

El monasterio de Santa Clara es el edificio colombino de Moguer. Su fábrica gótico-mudéjar nos transporta a épocas de esplendor y poderío. Fue fundado en 1337 por Alonso Jofre Tenorio, almirante mayor de Castilla, para religiosas clarisas de la orden de San Francisco. De aspecto robusto, como si de una fortaleza se tratara, acoge en su planta irregular el templo de tres naves rematado con nervaduras góticas, en cuyo presbiterio se encuentra el cenotafio de los fundadores. El claustro principal o de las Madres es del siglo XIV; de estilo mudéjar, es el más antiguo de Andalucía; la doble galería sustentada por columnas de mármol toscanas es una ampliación de la segunda mitad del siglo XVI. De esta época son las construcciones y las reformas
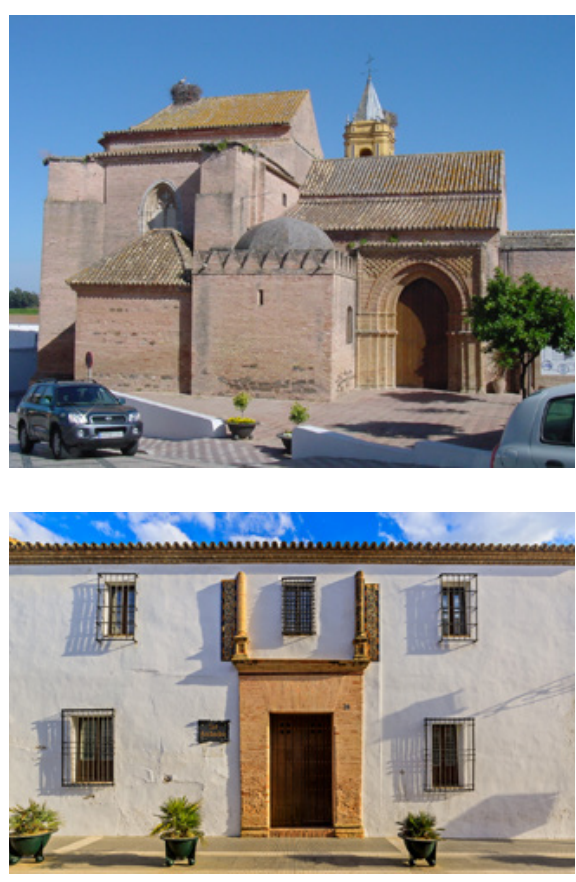

A la izquierda, iglesia de San Jorge Mártir. Palos de la Frontera | foto Miguel Ángel Muñoz

A la derecha arriba, iglesia de San Jorge Mártir. Puerta de los Novios. Palos de la Frontera | foto Diego Ropero

Casa Museo de Martín Alonso Pinzón. Palos de la Frontera | foto Miguel Ángel Muñoz

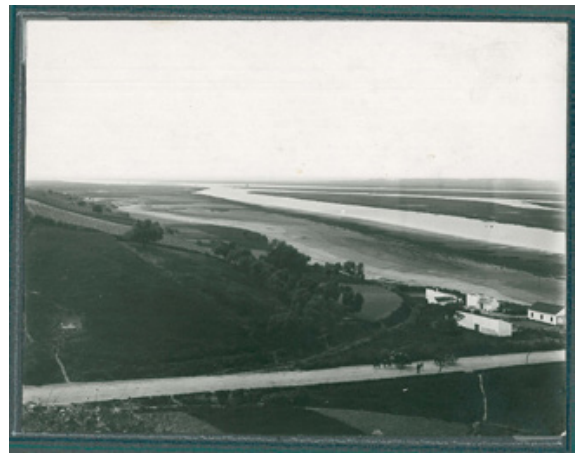

Arrecife y el río de Moguer. Principios del siglo XX | foto Archivo Histórico Municipal de Moguer 

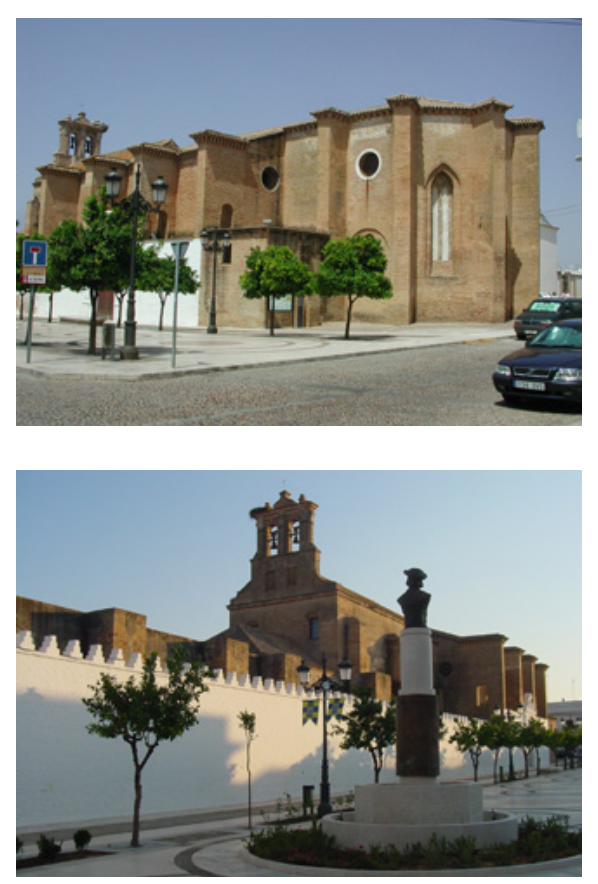

Arriba, ábside de la iglesia del monasterio de Santa Clara. Moguer

Abajo, monasterio de Santa Clara y el monumento a Colón. Moguer

A la derecha, castillo de Moguer | fotos Diego Ropero

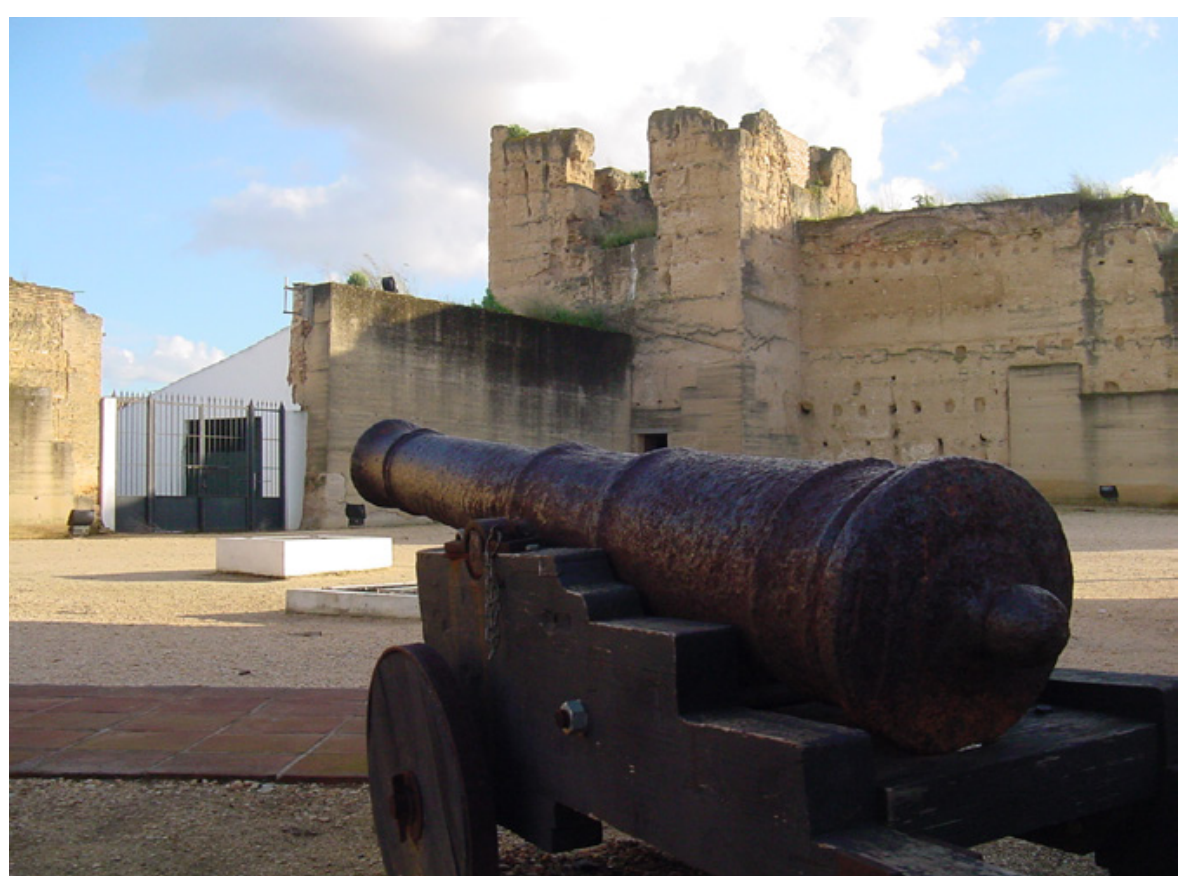

más importantes, como los dormitorios y la enfermería, a la que se llega a través del claustrillo mudéjar del siglo XV. Este modelo de construcción se reproduce en las iglesias fortificadas del valle de México y los claustros de la ciudad de Tunja (Colombia). En el interior del monasterio destacan, además del panteón de los fundadores, la sillería nazarí y las pinturas del coro bajo, y el retablo mayor, obra realizada por Jerónimo Velázquez en 1642. Cristóbal Colón oró e hizo decir una misa de acción de gracias en el interior del templo de las clarisas a su regreso del viaje de descubrimiento.

En sus inmediaciones, se encuentra el convento de San Francisco, edificio manierista sede del Archivo Histórico Municipal y la Biblioteca Iberoamericana, institución que contribuye a defender y proyectar la vocación americanista de Moguer. Merecen atención también el castillo medieval, la capilla del antiguo hospital del Corpus Christi, el ayuntamiento y la parroquia, estos dos últimos de la segunda mitad del siglo XVIII. Recorrer las calles de su casco histórico nos traslada a otras urbes hispanoamericanas, pues las relaciones con América fueron, durante siglos, una realidad ininterrumpida. La figura de Juan Ramón Jiménez, exiliado con su esposa Zenobia a América al inicio de la Guerra Civil, ha contribuido a conectar aún más ambas orillas. La casa museo del poeta reúne su biblioteca y muchos de los muebles y enseres que pertenecieron a la pareja.

Los lugares colombinos se localizan en la zona agroindustrial de Huelva, en cuya capital se encuentra el santuario de la Cinta, otro hito colombino que 


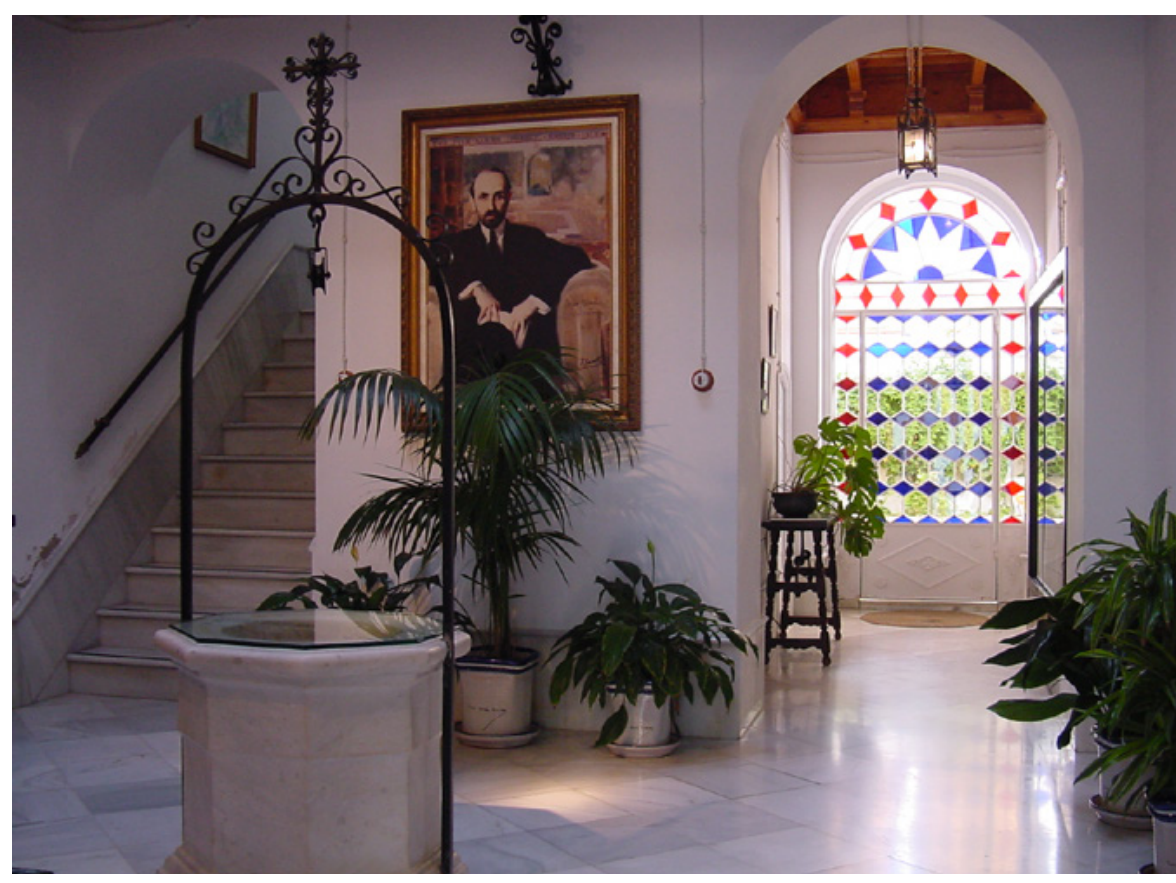

destacó como centro devocional entre la marinería. El estuario del río Tinto está considerado lugar de importancia comunitaria. En su entorno hallamos espacios protegidos como las marismas del Odiel (reserva de la Biosfera), el estero de Domingo Rubio y las lagunas de Palos y las Madres, que es paraje natural, y el Parque Nacional de Doñana, declarado Patrimonio de la Humanidad. Se trata de un paisaje de marismas de alto valor ecológico donde existe una variada avifauna acuática, invertebrados, anfibios y peces entre praderas de espartinas, almajos, verdolagas de mar y fangos. El sotobosque acoge una amplia extensión de pinos que en las últimas décadas se ha reducido para dar paso a las plantaciones de fresas.
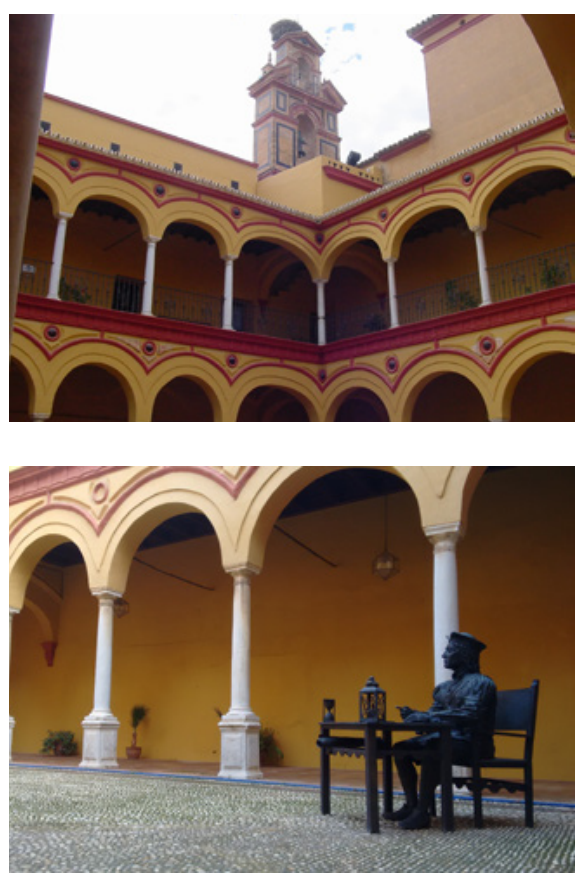

Claustro del convento de San Francisco, sede del Archivo Histórico Municipal. Moguer

Monumento al piloto Pedro Alonso Niño. Claustro de San Francisco. Moguer

Casa Museo de Zenobia y Juan Ramón Jiménez. Moguer | fotos Diego Ropero 